\title{
Considerations for mandatory childhood immunization programs
}

\author{
Noni E MacDonald, Eve Dubé2 ${ }^{1}$ Daniel Grandt ${ }^{3}$
}

\begin{abstract}
Outbreaks of vaccine preventable diseases occur even in countries that have unrestricted and relatively equitable accesses to immunizations because vaccine uptake rates are lower than necessary for effective disease control. Vaccine hesitancy is seen in many countries, including Canada, and has led to enacting or strengthening legislation requiring mandatory childhood immunization in some provinces. Although mandatory immunization may seem to be the simplest solution to this issue, it is not always as effective as anticipated. Different countries/states/provinces/territories have used different strategies to encourage parents to fully immunize their children. Definition, scope, flexibility (such as exemptions for medical, religious and philosophical reasons) and framework factors (such as strictness of application and levels of enforcement of the mandate) vary widely between jurisdictions. Surprisingly, no marked differences were seen in vaccination rates between countries that recommended versus mandated them. Unintended consequences of mandatory immunization programs-both good (increased availability of data) and bad ("gaming" of the system and disproportionate impacts on families of lower socioeconomic status) have been reported. Addressing lower vaccine uptake rates is a complex problem that needs a multipronged, more nuanced and tailored approach.
\end{abstract}

This work is licensed under a Creative Commons Attribution 4.0 International License.

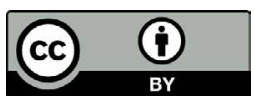

Affiliations

1 Department of Pediatrics, Dalhousie University, IWK Health Centre, Halifax, NS

2 Quebec National Institute of Public Health, Department of Anthropology, Laval University, Québec, QC

${ }^{3}$ Department of Internal Medicine, Klinikum Saarbruecken, Germany

\section{*Correspondence:}

noni.macdonald@dal.ca

Suggested citation: MacDonald NE, Dubé E, Grandt D. Considerations for mandatory childhood immunization programs. Can Commun Dis Rep 2020;46(7/8):247-51. https://doi.org/10.14745/ccdr.v46i78a06

Keywords: childhood immunization, mandatory, CANVax

\section{Introduction}

Outbreaks of vaccine preventable diseases occur even in highincome countries that have unrestricted and equitable access to immunizations. The reason for these outbreaks is that vaccine uptake rates are not where they need to be for adequate control of vaccine preventable diseases. Parents in many jurisdictions, including Canada, have been hesitant about immunizing their infants and children on time and on schedule (1). As a consequence, several countries have discussed, enacted or strengthened mandatory childhood immunization legislation to address this vaccine hesitancy problem (2-4). Mandatory immunization is seen as a "simple" solution to the problem. Historically, three factors appear to act as triggers for the implementation of mandatory childhood immunizations: failure of incentives to achieve desired vaccine uptake rates; response to a vaccine preventable disease outbreak that is difficult to control because of lower than desired vaccine uptake rates; and the push to achieve a vaccine preventable disease elimination goal, such as for polio (5).

Given that queries have also been raised in the press about whether coronavirus disease 2019 (COVID-19) vaccine(s), when available, should be made mandatory for some or all in Canada, this Canadian Vaccination Evidence Resource and Exchange Centre (CANVax) Brief provides an overview and brief discussion of what mandatory childhood vaccination means followed by discussions of scope and framework factors to consider. Also discussed are the reported outcomes, including reports of unintended consequences.

This is the sixth in a series of articles, produced by CANVax, an online database supporting immunization program planning and delivery. This series includes both the identification of existing resources and the description of the new resources developed by a multidisciplinary group of professionals (6). The article is one of a series and shows how the various aspects of vaccine hesitancy that have been considered to date can be applied to fostering vaccine acceptance.

\section{Definition, scope and frameworks of mandatory immunization programs}

In 2010, an expert group proposed the definition that a "mandatory" vaccine is one that every child in the country/state/ 
province/territory must receive by law without the option for the parent to accept or refuse it, independent of whether a legal or economical implication or sanction exists for the refusal (7). Mandatory immunization programs vary widely. There is neither a uniform approach for establishing mandatory immunization programs nor a common scope for such programs. Hence, it is critical when discussing any mandatory program for childhood vaccinations (and/or for other age groups) to understand what that program entailed and what it was hoped that program would achieve.

With respect to childhood immunizations, the scope of the mandate may apply to the entire country (Italy (3) and France (3)) or to specific constituent states, territories or provinces (California, United States (US) (3) and Ontario, Canada (8)), or it may apply more narrowly to a defined subset of the child population (9). Some programs cover most but not all of the World Health Organization (WHO) recommended childhood vaccines (e.g. Italy (3)), another may identify a limited range of vaccines (e.g. France, a specific list (3)) and another only one vaccine (Belgium, polio vaccine (10)). Some may specify an age group or milestone such as on school entry (Italy on enrolment in kindergarten) (3) and California, US, on school entry). With respect to flexibilities, some contain exemptions for medical contraindications only, while others include or previously included exemptions for religious and philosophical reasons (California, US (4) and Australia (11) prior to 2016).

Framework factors, such as strictness of application and levels of enforcement of the mandate, also vary, as can the body responsible for enforcement of the mandatory requirements (California, US) (4). Other programs may not enforce the mandate at all (Serbia). The program may focus on financial incentives to encourage compliance (11) or impose penalties that maybe financial or social (e.g. children can be precluded from daycare (Ontario, Canada (12) and Australia (11)) or school entry (California, US). Individuals may be precluded from access to theme parks (California, (12)) or they may be fined (Slovenia (10)) or even imprisoned (Uganda (13)).

There is a wide diversity of approaches to mandatory childhood immunization required by law:

- $\quad$ No enforcement, anyone can opt out without penalty (e.g. France before changes in 2018 (2))

- Opt out due to personal or philosophical objection without penalty (e.g. Ontario before changes in 2016 (14))

- Laws requiring parental education about immunization (rather than immunization itself); opt out with personal or philosophical objection but requires specific forms and notarization but no penalty for noncompliance (e.g. Ontario (8))

- Laws requiring immunization but opt out with personal or philosophical objection that requires specific forms and added effort. There is a penalty for noncompliance and strict enforcement (e.g. Australia before changes in 2016 (11))
- Laws requiring immunization with serious financial penalties or social restrictions; only allowing medical exemptions; strict enforcement (e.g. California, US after $2016(4,15)$ and Australia after 2016 (11))

\section{Outcomes of mandatory immunization programs}

There are surprisingly few systematic reviews, and very little comparative evidence on the outcomes of mandatory infant and childhood immunization programs. A 2006 report noted no strong difference in vaccination rates between countries that only recommend certain vaccinations and countries that mandate them (16). A 2016 systematic review of outcomes of mandates found only 11 before and after studies, and 10 studies comparing immunization rates in similar populations with and without mandates. Overall, the authors concluded that mandatory immunization was generally helpful to increase vaccine uptake rates, albeit 18 of the included studies originated from one country, the US, with only two from Canada and one from France (17). This review did not assess the impact of mandatory immunization on attitudes toward immunization.

In 2018, a landscape review of the legislative environment for childhood immunization was conducted in 53 countries of the European region (18). Findings of this review showed a diversity of legislative frameworks for immunization (from recommendations to strong mandatory policies) with no clear evidence for the "best approach" to enhance vaccine uptake and acceptance (i.e. uptake rates did not correlate with presence or absence or type of legislation). To interpret the results correctly it is necessary to understand the differences that exist between mandatory immunization programs in a historical and geographical context. The 15 ethnic Republics that composed the former United Soviet Socialists Republic and its communist neighbours all had very strong centralized public health systems with mandatory vaccination that enabled enforcement without question and was associated with high uptake rates. By 2018, however, much had changed with respect to childhood immunization in many of these countries. By 2018, Ukraine had the lowest childhood vaccine uptake rate in the WHO European Region, and Serbia and Poland had experienced protests against mandatory immunizations.

There have not been studies of mandates in high-income countries in jurisdictions with relatively high baseline rates or with mandates for child-care centers. In Belgium and Italy, for example, some vaccines were mandatory for historical reasons and others were not. Non-mandatory vaccines may have been perceived by the public and health care professionals as being less important and less necessary. In Italy, this divergence in the program led to high coverage (all greater than 93\%) of the mandatory vaccines (e.g. diphtheria, tetanus, poliomyelitis and hepatitis B) but lower than needed coverage of other 
recommended but not mandated vaccines (e.g. measles coverage was $87 \%$ ) (3). Measles outbreaks led Italy to move to broader mandatory immunization (3).

In Australia, in 2015, due to concerns about uptake rates, the No Jab No Pay amendment bill removed the vaccination "conscientious objection" exemption to vaccination requirements (11). By March 2017, these changes were associated with an increase in vaccine uptake among five-year olds from $92.59 \%$ to $94.34 \%$ (10) but, as noted below, the impact of the change was not uniform across socioeconomic classes.

In Ontario, tightening of the mandatory process required to obtain a philosophical exemption has revealed valuable information, as this newly available record-level data has permitted more detailed analysis (19). In 2016-2017, 2.4\% of students had a non-medical exemption to at least one antigen; however, there were also students who were not yet immunized but who had not requested an exemption. Furthermore, having a signed non-medical exemption did not always correlate with non-immunization. The likelihood of having a non-medical exemption and not being immunized was higher for private or other non-government funded schools and specific geographic areas. In addition, older and/or disadvantaged students were less likely to have a non-medical exemption.

\section{Unintended consequences of mandatory immunization programs}

Mandatory immunization programs have the potential for unintended consequences. The removal of non-medical exemptions (i.e. personal belief exemptions) has led to an increase in medical exemptions in California, US (20) and Australia (11). Regions with high previous rates of personal exemptions before the instigation of more restrictive laws appear to develop higher rates of medical exemptions. This suggests a "gaming" of the system. Disappointingly, the target population response has been to seek medical exemption rather than to accept immunization.

In Australia, the No Jab No Pay mandatory childhood immunization program did increase immunizations as noted above; but disproportionately children and families living in poverty were most negatively affected, leading to equity and justice concerns (11).

An unintended benefit of mandatory programs is the requirement for greater attention to data collection on who is immunized. This was notable in Ontario where time, attention and funds were paid to make the childhood immunization registry functional.

\section{COVID-19 vaccines and consideration for a mandatory approach}

While a poll in Canada in late April 2020 reported strong support amongst the general public for making COVID-19 vaccination mandatory (21), this strategy can only be considered when these vaccines become widely available in Canada. Given that a mandatory program has costs both in terms of implementation and monitoring (5), decisions need to rest on what additional benefit is hoped to be achieved. If vaccine uptake is already expected to be high amongst groups deemed necessary for the control of the spread of COVID-19, then the added costs of a mandatory program are likely not justified. In contrast, if the rates of uptake are low and the ease of access and other strategies known to improve uptake have been addressed, then a mandatory approach may be worth pursuing. Careful attention must be paid to whether this will be an incentive or penalty program, how it will be monitored and by whom (5).

\section{Conclusion}

There is no standard global approach to mandatory immunizations. Which vaccines are included, which age groups are covered, program flexibility and rigidity (e.g. opportunities for opting out, penalties or incentives and degree of enforcement) all have to be considered. Mandatory immunization for childhood vaccines is no guarantor that the problem of lower-than-desired vaccine uptake rates will be overcome, although it can lead to increased uptake. There were no strong differences in vaccination rates between countries that only recommend certain vaccinations and countries that mandate them. Context matters; different countries have implemented or not implemented mandatory immunization for different reasons, different circumstances and used different approaches. Furthermore, unintended consequences like a reduced acceptance rate of non-mandatory immunizations needs to be anticipated as well as the possibility of vaccine-hesitant individuals gaming the system. Rigid mandatory vaccination requirements may appear, at the first sight, to be the simple solution to improving vaccine uptake rates; however, evidence does not strongly support this conclusion. Mandatory immunization is but one strategy to consider. Addressing lower vaccine uptake rates is a complex problem that needs a multipronged, more nuanced and tailored approach (22).

\section{Authors' statement}

NEM - Writing original draft

ED - Writing, review \& editing

DG — Writing, review \& editing

\section{Competing interests}

Dr. MacDonald reports grants from the Public Health Agency of Canada, the Canadian Institutes of Health Research, Nova Scotia Health Authority, IWK Health Authority and the Canadian 
Immunization Research Network. Dr. Dubé reports grants from the Public Health Agency of Canada, the Quebec Ministry of Health and Social Services, le Fonds de la recherche en Santé du Québec, the Canadian Institutes of Health Research, the Canadian Immunization Research Network, and the Social Sciences and Humanities Research Council of Canada.

\section{Acknowledgements}

Contributions to Canadian Vaccination Evidence Resource and Exchange Centre (CANVax) come from a very wide range of authors, committees, immunization partners, reviewers and especially the CANVax secretariat at Canadian Public Health Association.

\section{References}

1. Lane S, MacDonald NE, Marti M, Dumolard L. Vaccine hesitancy around the globe: analysis of three years of WHO/ UNICEF Joint Reporting Form data-2015-2017. Vaccine 2018;36(26):3861-7. DOl PubMed

2. Ward JK, Colgrove J, Verger P. Why France is making eight new vaccines mandatory. Vaccine 2018;36(14):1801-3. DOI PubMed

3. Ricciardi W, Boccia S, Siliquini R. Moving towards compulsory vaccination: the Italian experience. Eur J Public Health 2018;28(1):2-3. DOI PubMed

4. Delamater PL, Leslie TF, Yang YT. Change in medical exemptions from immunization in California after elimination of personal belief exemptions. JAMA 2017;318(9):863-4. DOl PubMed

5. MacDonald NE, Harmon S, Dube E, Steenbeek A, Crowcroft N, Opel DJ, Faour D, Leask J, Butler R. Mandatory infant \& childhood immunization: Rationales, issues and knowledge gaps. Vaccine 2018;36(39):5811-8. DOI PubMed

6. Canadian Public Health Association. The Canadian Vaccination Evidence Resource and Exchange Centre. Ottawa (ON): CANVax (accessed 2019-12-15).

https://www.canvax.ca

7. Haverkate M, D'Ancona F, Giambi C, Johansen K, Lopalco PL, Cozza V, Appelgren E; VENICE project gatekeepers and contact points. Mandatory and recommended vaccination in the EU, Iceland and Norway: results of the VENICE 2010 survey on the ways of implementing national vaccination programmes. Euro Surveill 2012;17(22):20183. DOI PubMed

8. Dyer O. Ontario suspends unvaccinated children from school and proposes mandatory classes for parents. BMJ 2015;351:h6821. DOI PubMed

9. Yezli S. The threat of meningococcal disease during the Hajj and Umrah mass gatherings: A comprehensive review. Travel Med Infect Dis Jul - Aug 2018;24:51-8. DOI PubMed
10. Walkinshaw E. Mandatory vaccinations: the international landscape. CMAJ 2011 Nov;183(16):E1167-8. DOI PubMed

11. Leask J, Danchin M. Imposing penalties for vaccine rejection requires strong scrutiny. J Paediatr Child Health 2017 May;53(5):439-44. DOI PubMed

12. Government of Ontario. Child Care and Early Years Act, 2014, S.O. 2014, c. 11, Sched. 1. Immunization. https://www.ontario.ca/laws/regulation/150137\#BK46

13. Uganda Legal Information Institute. Immunisation Act, 2017. https://ulii.org/node/27644

14. Wilson SE, Seo CY, Lim GH, Fediurek J, Crowcroft NS, Deeks SL. Trends in medical and nonmedical immunization exemptions to measles-containing vaccine in Ontario: an annual cross-sectional assessment of students from school years 2002/03 to 2012/13. CMAJ Open 2015;3(3):E317-23. DOI PubMed

15. Zipprich J, Winter K, Hacker J, Xia D, Watt J, Harriman K; Centers for Disease Control and Prevention (CDC). Measles outbreak--California, December 2014-February 2015. MMWR Morb Mortal Wkly Rep 2015;64(6):153-4. PubMed

16. Salmon DA, Teret SP, Maclntyre CR, Salisbury D, Burgess MA, Halsey NA. Compulsory vaccination and conscientious or philosophical exemptions: past, present, and future. Lancet 2006;367(9508):436-42. DOI PubMed

17. Lee C, Robinson JL. Systematic review of the effect of immunization mandates on uptake of routine childhood immunizations. J Infect 2016;72(6):659-66. DOI PubMed

18. Sabin Vaccine Institute. Legislative Landscape Review: Legislative Approaches to Immunization Across the European Region. Washington (DC): Sabin Institute; 2018. https://www.sabin.org/sites/sabin.org/files/legislative_ approaches_to_immunization_europe_sabin_0.pdf

19. Wilson SE, Murray J, Bunko A, Johnson S, Buchan SA, Crowcroft NS, Dubey V, Loh LC, MacLeod M, Taylor C, Deeks SL. Characteristics of immunized and un-immunized students, including non-medical exemptions, in Ontario, Canada: 2016-2017 school year. Vaccine 2019;37(23):312332. DOI PubMed

20. Delamater PL, Pingali SC, Buttenheim AM, Salmon DA Klein NP, Omer SB. Elimination of nonmedical immunization exemptions in California and school-entry vaccine status. Pediatrics 2019;143(6):e20183301. DOI PubMed

21. Leger. Concerns about COVID-19 - April 28, 2020. https://leger360.com/surveys/concerns-about-covid-19april-28-2020/

22. Dubé E, Bettinger JA, Fisher WA, Naus M, Mahmud SM, Hilderman T. Vaccine acceptance, hesitancy and refusal in Canada: challenges and potential approaches. Can Commun Dis Rep 2016;42(12):246-51. DOI PubMed 

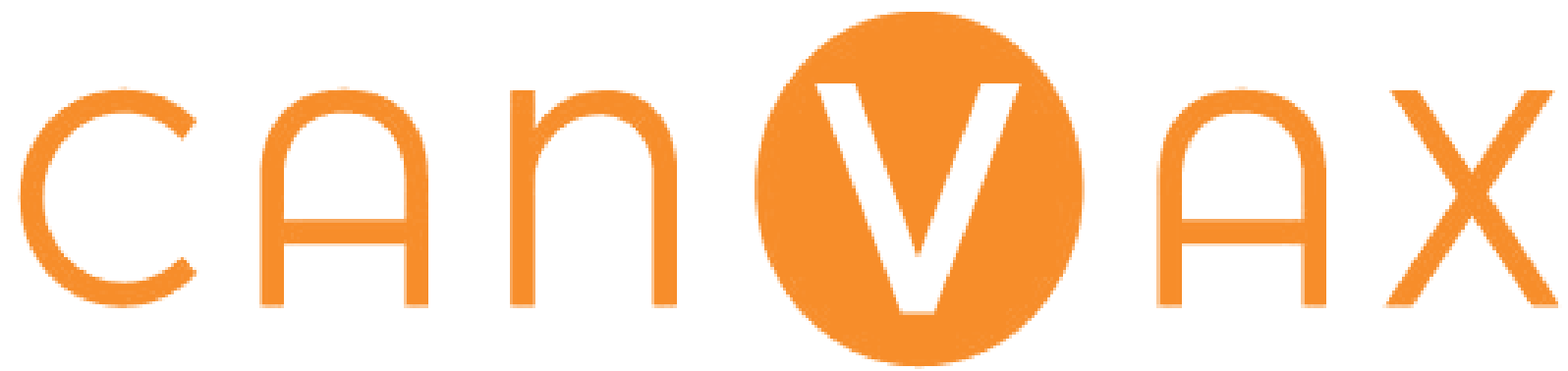

CANVax is the first online resource of its kind in Canada to equip public health professionals with access to a centralized resource centre focused on vaccine acceptance and uptake.

\section{https://www.canvax.ca/}

\section{ALREADY PUBLISHED IN CCDR}

A new resource to summarize evidence on immunization from the Canadian Vaccination Evidence Resource and Exchange Centre

(CANVax) - CCDR Vol. 46 No. 1 (January 2, 2020)

Promoting immunization resiliency in the digital information age - CCDR Vol. 46 No. 1 (January 2, 2020)

Optimizing communication material to address vaccine hesitancy - CCDR Vol. 46 No. 2/3 (February 6, 2020)

Motivational interviewing: A powerful tool to address vaccine hesitancy - CCDR Vol. 46 No. 4 (April 2, 2020)

Vaccine acceptance: How to build and maintain trust in immunization - CCDR Vol. 46 No. 5 (May 7, 2020)

Managing immunization stress-related response: A contributor to sustaining trust in vaccines - CCDR Vol. 46 No. 6 (June 4, 2020) 